\title{
VARIATIONS IN ENERGY EXPENDITURE DURING WALKING
}

\author{
BY \\ C. DELBUE, ${ }^{*}$ R. PASSMORE, J. THOMSON, and J. A. WATT \\ From the Department of Public Health and Social Medicine, and the Department of Physiology, \\ University of Edinburgh
}

Wide individual variations exist in energy intake as food. Our own observations of the calorie values of the diets of Edinburgh University students (Kitchin, Passmore, Pyke, and Warnock, 1949), together with those of Cook (1948) on Dundee students and of Widdowson (1947) on middle class boys before the second world war, are shown in Table I. This table is indeed only a quantitative statement of the extent of variations already familiar to all those responsible for feeding young men. But, though the variations are well known, the factors responsible for them are not easy to determine. Those of the Edinburgh. students, we think, cannot be accounted for entirely by differences in external work carried out. Thus the survey took place during the winter months when daylight was. short and active outdoor exercise was limited to the week-ends. For five days of the week, at least, these students could with reason be classified as "sedentary workers".

TABLE I

Variations in Daily Intake of Calories by Healthy YOUNG MEN

\begin{tabular}{|c|c|c|c|}
\hline & $\begin{array}{c}\text { Edinburgh } \\
\text { students }\end{array}$ & $\begin{array}{l}\text { Dundee } \\
\text { students } \\
\text { (Cook) }\end{array}$ & $\begin{array}{l}\text { Middle- } \\
\text { class boys } \\
\text { (Widdow- } \\
\text { son) }\end{array}$ \\
\hline $\begin{array}{l}\text { Number surveyed } \\
\text { Age .. } \\
\text { Mean daily Calorie }\end{array}$ & $\begin{array}{c}127 \\
19-21\end{array}$ & $\begin{array}{c}44 \\
17-31\end{array}$ & $\begin{array}{l}20 \\
18\end{array}$ \\
\hline intake & 2,970 & 2,878 & 3,427 \\
\hline $\begin{array}{l}\text { Minimum dally Cal- } \\
\text { orie intake } \\
\text { Maximum daily } \mathrm{Cal}\end{array}$ & 2,140 & 1,994 & 2,338 \\
\hline $\begin{array}{l}\text { orie intake } \\
\text { Standard deviation }\end{array}$ & $\begin{array}{c}4,690 \\
518\end{array}$ & $\begin{array}{l}3,595 \\
409\end{array}$ & 5,221 \\
\hline $\begin{array}{ccc}\text { tion } & \cdots & .\end{array}$ & $17 \cdot 4$ & $14 \cdot 4$ & $20 \cdot 4$ \\
\hline
\end{tabular}

However great the variations in physical activity at the week-end, it is hard to believe that this factor

* British Council scholar from Buenos Aires. alone could account for the wide variations in food intake spread throughout the week of each survey.

The possibility exists that those who consume less food are more economical machines ; they can go " more miles to the gallon". In carrying out a set piece of mechanical work these small eaters may need less energy than the big eaters. To test this hypothesis we have measured the variations in the energy expenditure of a group of 50 young men, half of whom had previously taken part in our diet survey, during the performance of a standard task. Walking at a fixed speed was chosen, as it seemed to be the one physical activity which must be common to all and in which all would be in daily training and practice.

Any successful correlation between the variations in individual energy intake and output might be expected to throw some light on the important nutritional and social problem of obesity. Although in the final analysis obesity is a simple disturbance of the balance of energy, the mechanism and causes of the upset of the balance are far from being fully understood. Obesity is the most important nutritional disease in Scotland to-day. Our colleague, Dr. Meiklejohn, tells us that, judging from his experience in the Dietetic Department of the Edinburgh Royal Infirmary, he guesses that out of the half million citizens of Edinburgh, at least ten thousand are so much overweight as to constitute a serious menace to health. Studies in variation of energy utilization may be basic to an understanding of the real cause of the disorders of these people, who, for the most part, cannot be dismissed as simple gluttons.

\section{MethodS}

Energy utilization was determined by indirect calorimetry using the Douglas bags and Haldane gas analysis apparatus (Douglas and Priestley, 1948).

Fifty male students from the physiology class acted as subjects. Their ages varied from 19 to 27 , the average being 20 years 4 months. They formed a homogeneous group, and variations in height, weight, and vital capacity are recorded in Table II. Twenty-five had taken part in the diet survey previously reported (Kitchin and others, 
1949), and figures for Calorie consumption over a week were available. Unfortunately, the interval between the measurement of dietary intake and energy expenditure was 15 months.

For an assessment of basic energy expenditure, oxygen consumption was recorded in a resting condition. The routine of the observations was as follows.

Volunteers, with whom arrangements had previously been made, reported at 2 p.m. in the laboratory after the normal 1 to 2 o'clock luncheon break. After being weighed and measured, they rested, lying on a couch, for 30 minutes. Resting oxygen levels were determined between 2.45 and 3 p.m. The walking was then carried out on a paved outdoor track. The standard pace was 90 metres per minute (3.35 m.p.h.), and this was checked at 20 second intervals. No difficulty was found in maintaining a uniform speed. Expired air was collected over approximately three-minute periods.

All students then carried out the Harvard step test of physical efficiency (Brouha, Fradd, and Savage, 1944). In this the subject steps up and down 30 times a minute for five minutes on to a 20 -in. stool or platform. This is a severe test. Those who cannot complete it are given an arbitrary assessment based on partial performance. Those who complete the test have an index allotted them on a scale based on measurements of pulse rates during the four minutes subsequent to the exercise.

\section{RESULTS}

Table II shows the mean range, standard deviation, and coefficient of variation of all our observations. Fig. 1 is a scatter diagram on which are plotted the $\bar{C}$ rates of oxygen utilization during a standard walk against previously determined Calorie consumption per day. The diagram shows no evidence of any $\mathbb{D}$ correlation. Both sets of figures are uncorrected for size. We have attempted correlations between figures derived from these basic data in which corrections for size have been incorporated. However, we have been unable to derive any evidence of $\mathscr{} \rho$ a relationship between the efficiency of energy $\frac{\bar{D}}{}$ expenditure and average food consumption. This, ? of course, does not mean that such a relationship $\omega$ may not exist. With our methods we have only been able to sample brief periods of behaviour for $\omega$ measurements. We can only conclude that such 음 a relationship, if it exists, is not very close and, to demonstrate it, observations on a scale altogether greater than ours would be necessary.

Although the main result of these experiments is $\overrightarrow{0}$ negative, certain subsidiary points of interest arise. $\frac{t}{0}$ In Fig. 2, variations in energy expenditure during

TABLE II

Physiological Variations (50 young men)

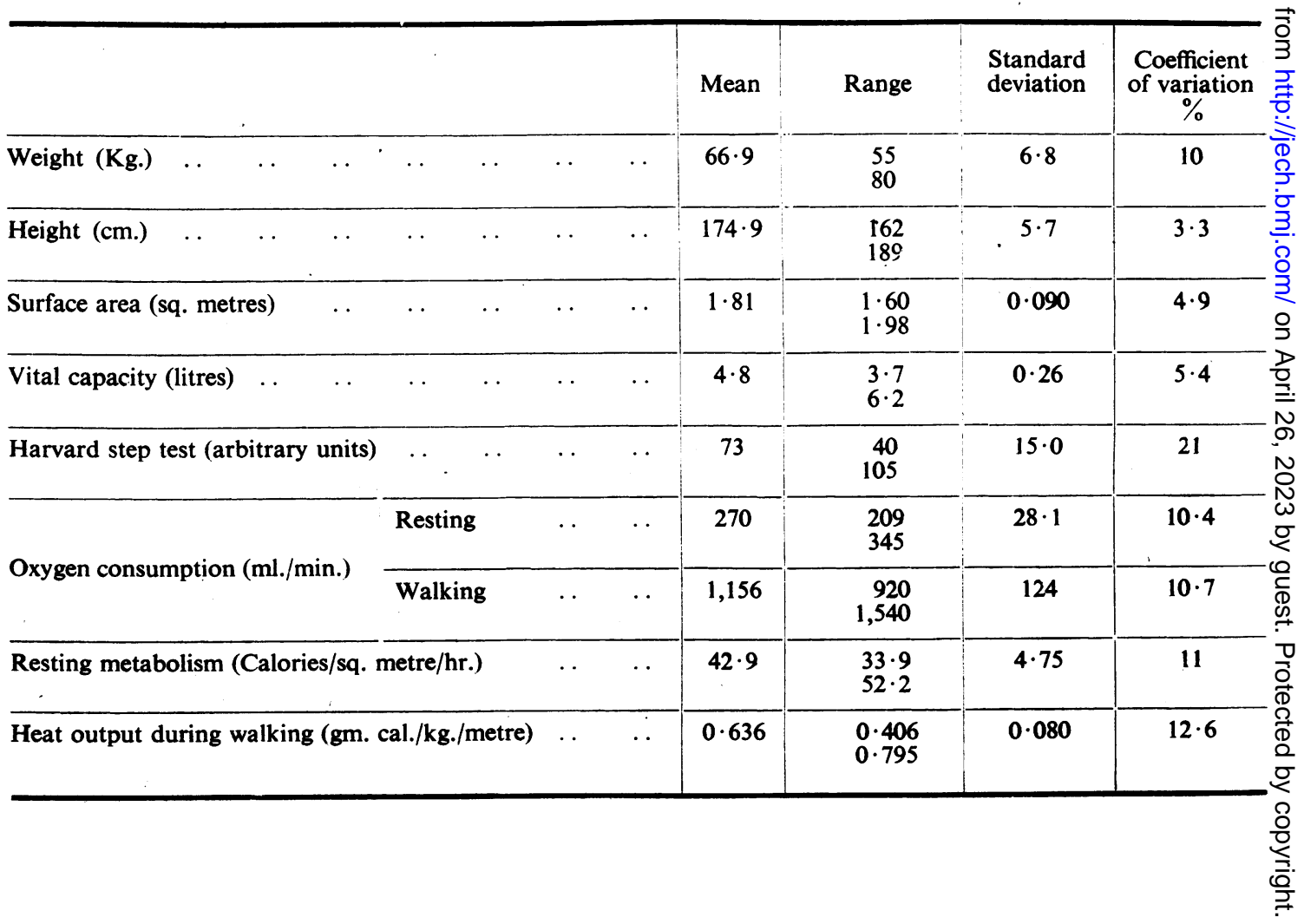


walking are plotted. The energy expenditure is calculated in gm.-calories per kilo bodyweight per metre, in line with the classic studies on energy transformation during horizontal walking by Benedict and Murschhauser (1915).

For the base line, estimations of resting metabolism after food have been taken. Although theoretically this is much less satisfactory than determination of basal metabolism, practical difficulties arise in measurements of B.M.Rs on a large scale. It is satisfactory, therefore, to find that our determinations for resting metabolism agree well with the findings of Cathcart and Orr (1919) on young infantry recruits. These observers found an average B.M.R. of 37.8 Calories per sq. metre per hour for the comparable group of young men. The increase in lying rate after meals was found to be 12 per cent., giving a figure for a " resting metabolism" of $42 \cdot 3$, with which our figure of $42 \cdot 9$. recorded in Table II, agrees closely. Benedict and Murschhauser's observations are very detailed and precise, but cover only two subjects, both professional athletes. They found that a change from a lying to a standing position resulted in increases in metabolism of 9 and 10 per cent. respectively in the two subjects. Our calculations of heat output during walking are made after subtraction of the individual observed value for energy expenditure resting after food.

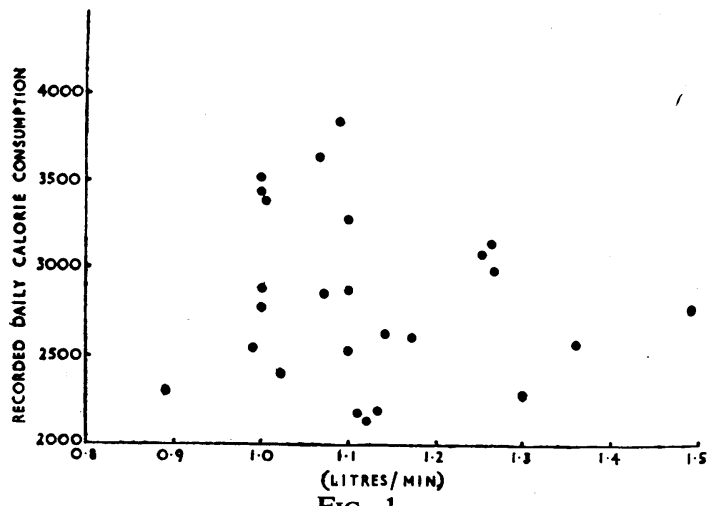

Fig. 1.

Oxygen utilization walking at 90 metres per minute.

The relationships between energy expenditure and weight and height are complex. A part of the work done in walking consists in raising the centre of gravity of the body at each step. In fact, in expressing energy during walking in gm. cal./kilo/metre, Benedict and Murschhauser assumed that with increasing weight an increasing expenditure of energy ensues. Our figures do not provide a complete justification for this assumption. The correlation between weight and the extra oxygen utilization on walking only gives a coefficient $r=0.225$ and $t=1 \cdot 59$. This is not a significant degree of correlation, although it is suggestive. The reason for this is undoubtedly the complex relationship between weight and height and energy expenditure. With extra weight there is usually extra height, and this means longer legs, fewer steps, and less raising of the body. Unfortunately, we neither measured the length of legs of our subjects nor counted their steps when walking. Over the whole height range

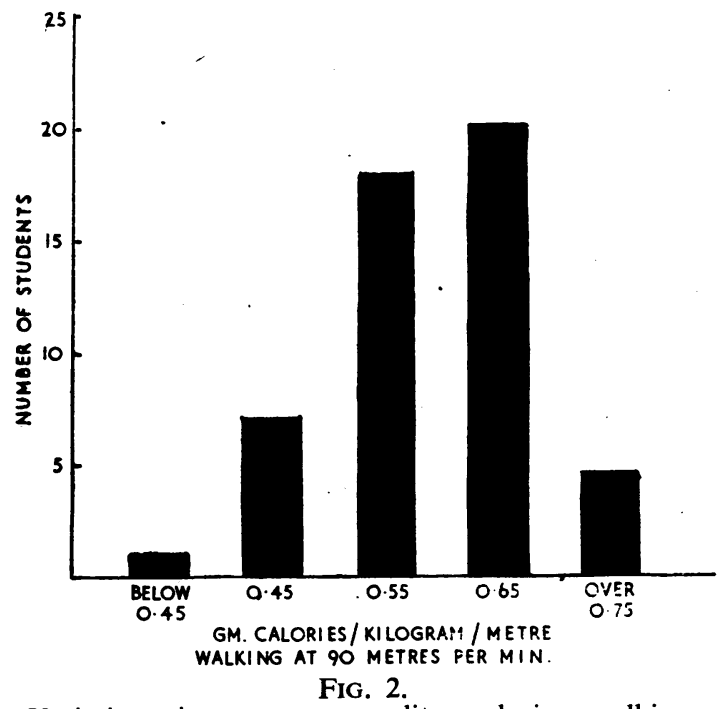

Variations in energy expenditure during walking.

our figures show no correlation between height and energy expenditure, but the small men were all above the average figure for energy expenditure expressed in gm. cal./kilo/metre. Thus nine men in the group with heights below $170 \mathrm{~cm}$. (5 ft. 7 in.) had an average figure of 0.714 , compared with the average of 0.621 for those over this height. The standard deviation of this difference gives a " $t$ " value greater than 5 , and the difference is statistically sound.

In walking, with increasing size, more weight has to be lifted but it does not have to be lifted so frequently. Thus size would appear to affect energy expenditure in two different directions. Our data make it clear that to work out the significance of these changes, observations on a series far larger than our present one of 50 would be necessary.

The degree of physical fitness might be thought to affect energy expenditure. Of our students, 23 gave Harvard step tests between 65 and 79 and were graded as average. Sixteen were above the standard, nine were below it, and two were considered unfit to take the test. The test is considered to 
compensate automatically for variations in size, and no correlation between performance and height or weight has been found (Selzer, 1946). We found no correlation between the test and walking energy expenditure.

\section{CONCLUSIONS}

These observations on physiological variations in healthy young men emphasize the wide range of normality. We feel that these variations in energy expenditure may lie near the root of the problem of obesity and that these further data on their nature are valuable and perhaps provocative.

Our observations also re-emphasize the difficulties of drawing up satisfactory tables of dietary requirements based on estimations of energy expenditure on different types of work. For instance, the specimen daily tables of energy expenditure drawn up by Orr and Leitch (1937), and used for assessing Calorie requirements, rely for their data in many respects on intelligent guessing. Basic information is lacking. Hitherto such tables have, of necessity, dealt with a mythical average man. Food administrators drawing up ration schedules have perforce to think in terms of such an average man. Yet many normal men differ profoundly from the average man. With the increasing group control of individual activities in our society, it is important for the individual that the group should know how individuals vary. A wider study of such variations in energy expenditure in performing standard tasks would be a useful aid to practical planners. The classical methods both of direct and indirect calorimetry, although exceedingly precise in skilled hands, are so laborious and time-consuming that in practice metabolic studies have for the most part been limited to detailed observations on a few
THOMSON, AND J. A. WATT

subjects. When newer methods of sampling expired $\frac{3}{\infty}$ air and fresh means of estimation of oxygen become ? available, it may be possible to extend the range of $\vec{F}$ : many of our basic observations over a much greater $\stackrel{\rho}{9}$ number of subjects, with a correspondingly greater $\bar{C}$ increase in accuracy. This would enable much $\frac{\bar{\sigma}}{\bar{D}}$ practical food planning to rest upon a sounder basis of scientific data.

\section{SUMMARY}

The energy expenditure of 50 healthy young men $\vec{\circ}$ was determined whilst walking under standard $\overrightarrow{\vec{\omega}}$ conditions. The mean value found was $0.636 \mathrm{gm}$. cal./kilo/metre, with variations between 0.406 and $\underset{0}{\circ}$ 0.795 .

No correlation could be found between these $\omega$ variations and the previously determined dietary intake of calories.

The relation with variations in height and weighto and in the Harvard step test for physical fitness is. discussed.

\section{REFERENCES}

Benedict, F. G., and Murschhauser, H. (1915). Carnegie $\vec{\ominus}$ Institute of Washington Publication, No. 231.

Brouha, L., Fradd, N. W., and Savage, B. M. (1944).. Res. Quart. Amer. Ass. Hlth phys. Educ. Recr., 15, 211.

Cathcart, E. P., and Orr, J. B. (1919). “"The Energy Expenditure of the Infantry Recruit in Training." H.M.S.O.

Cook, R. P. (1948). Brit. med. J., 2, 711.

Douglas, C. G., and Priestley, J." G. (1948). “ Human Physiology." 3rd ed. Oxford.

Kitchin, A. H., Passmore, R., Pyke, M., and Warnock, G. M. (1949). British Journal Social Medicine, 3, 10.

Orr, J. B., and Leitch, I. (1937). Nutr. Abstr. and Rev.;O 7, 509.

Selzer, C. C. (1946). Res. Quart. Amer. Ass. Hith phys. Educ. Recr., 17, 10.

Widdowson, E. M. (1947). Spec. Rep. Ser. Med. Res.' Coun., No. 257. London. 